\title{
The Role of Nitric Oxide and GluR1 in Presynaptic and Postsynaptic Components of Neocortical Potentiation
}

\author{
Neil Hardingham and Kevin Fox \\ School of Bioscience, Cardiff University, Cardiff CF10 3US, United Kingdom
}

In this study, we investigated the mechanisms underlying synaptic plasticity at the layer IV to II/III pathway in barrel cortex of mice aged 6-13 weeks. This pathway is one of the likely candidates for expression of experience-dependent plasticity in the barrel cortex and may serve as a model for other IV to II/III synapses in the neocortex. We found that postsynaptic autocamtide-2-inhibitory peptide is sufficient to block long-term potentiation (LTP) (IC I0 $_{500} \mathrm{nM}$ ), implicating postsynaptic calcium/calmodulin-dependent kinase II in LTP induction. AMPA receptor subunit 1 (GluR1) knock-out mice also showed LTP in this pathway, but potentiation was predominantly presynaptic in origin as determined by paired-pulse analysis, coefficient of variation analysis, and quantal analysis, whereas wild types showed a mixed presynaptic and postsynaptic locus. Quantal analysis at this synapse was validated by measuring uniquantal events in the presence of strontium. The predominantly presynaptic LTP in the GluR1 knock-outs was blocked by postsynaptic antagonism of nitric oxide synthase (NOS), either with intracellular $\mathrm{N}$ - $\omega$-nitro-L-arginine methyl ester or $\mathrm{N}$-nitro-L-arginine, providing the first evidence for a retrograde transmitter role for NO at this synapse. Antagonism of NOS in wild types significantly reduced but did not eliminate LTP (group average reduction of 50\%). The residual LTP formed a variable proportion of the total LTP in each cell and was found to be postsynaptic in origin. We found no evidence for silent synapses in this pathway at this age. Finally, application of NO via a donor induced potentiation in layer II/III cells and caused an increase in frequency but not amplitude of miniature EPSPs, again implicating NO in presynaptic plasticity.

\section{Introduction}

Plasticity mechanisms vary at different synapses (Nicoll and Malenka, 1995; Buonomano, 1999; Allen et al., 2000) and at different stages of development (Yasuda et al., 2003; Rumpel et al., 2004). Synaptic plasticity has perhaps been studied most extensively at the hippocampal Schaeffer collateral-CA1 synapse and, because of cell culture techniques and recording methods, more usually during development than in adulthood. However, the realization that plasticity mechanisms are numerous and that they vary at different locations in the brain and at different developmental stages leads naturally to widen the search for common principles (Malenka and Bear, 2004). A key set of synapses to understand in this regard are those of the neocortex. Cortical synapses are involved in a range of functions, including working and remote memory, as well as sensory map plasticity and motor adaptation, all of which are thought to require synaptic plasticity to operate. Neurons in layers II/III of the cortex are known to be particularly plastic not only in young animals but also in adults. The major input pathways to layer II/III cells arise from layer IV cells (Feldmeyer et al., 2002), and this pathway has been implicated in plasticity in vivo (Glazewski et al., 1996; Finnerty et al., 1999; Feldman, 2000; Takahashi et al., 2003). We therefore stud-

\footnotetext{
Received Feb. 14, 2006; revised May 24, 2006; accepted May 26, 2006.

We thank Rolf Sprengel for allowing the GluR1 knock-out mice to be used in this project, Emma Blain for measuring nitric oxide levels, and John Isaac for critically reading this manuscript.

Correspondence should be addressed to Kevin Fox, Cardiff University, Biosciences, Museum Avenue, CardiffCF10 3US, UK. E-mail: foxkd@cf.ac.uk.

DOI:10.1523/JNEUROSCI.0652-06.2006

Copyright $\odot 2006$ Society for Neuroscience $\quad$ 0270-6474/06/267395-10\$15.00/0
}

ied plasticity in this pathway in adult animals (age 6-13 weeks) to avoid developmental plasticity mechanisms such as silent synapses, which tend not to be present beyond 4 weeks in layers II/III of the cortex (Rumpel et al., 2004).

Layer II/III cells occupy an important position within the columnar architecture of the cortex for integration of information. The neocortex is composed of functional columns of cells that interconnect via horizontal and diagonal pathways. The intercolumnar pathways are important for map plasticity in sensory cortex (Buonomano and Merzenich, 1998) and more generally for forming associations between neighboring columns. The anatomical manifestation of the cortical column can be seen in layer IV of the barrel cortex (Woolsey and Van der Loos, 1970), which makes it a particularly good model for studying cortical plasticity. Receptive field plasticity can be induced in the cortex by whisker deprivation. Whisker deprivation leads to potentiation of spared whisker responses and depression of deprived whisker responses in the cortex, whereas thalamic responses remain constant (Fox, 2002). Lateral pathways between columns are required for expression of the potentiated spared whisker responses (Fox, 1994). The most direct pathway, although not the only pathway that might be responsible, runs from layer IV to layers II/III in the neighboring barrel column. In a previous study, we found that calcium/calmodulin-dependent kinase II (CaMKII) autophosphorylation plays a key role in synaptic potentiation in this pathway and that experience-dependent plasticity depends on the same mechanism (Hardingham et al., 2003). However, it is not known whether presynaptic or postsynaptic CaMKII is required for potentiation in the neocortex or what the effector molecules 
might be downstream of CaMKII. Therefore, in this study, we investigated plasticity mechanisms downstream of CaMKII in the layer IV to II/III pathway.

\section{Materials and Methods}

We used 6-13 week AMPA receptor subunit 1 (GluR1) knock-out mice and wild-type littermates bred into a C57BL/6 background and maintained the colony as heterozygotes. Experimental null mutants and wildtype littermates were bred from heterozygote crosses (cousin matings).

Drugs and solutions. Coronal slices $(400 \mu \mathrm{m})$ containing barrel cortex were maintained in a submersion chamber continually perfused (2-3 $\mathrm{ml} / \mathrm{min}$ ) with artificial CSF (aCSF) containing the following (in $\mathrm{mm}$ ): $119 \mathrm{NaCl}, 3.5 \mathrm{KCl}, 1 \mathrm{NaH}_{2} \mathrm{PO}_{4}, 2 \mathrm{CaCl}_{2}, 1 \mathrm{MgSO}_{4}, 26 \mathrm{NaHCO}_{3}$, and 10 glucose [bubbled with $5 \% \mathrm{CO}_{2}-95 \% \mathrm{O}_{2}$ at room temperature $\left(21-24^{\circ} \mathrm{C}\right)$ ]. To block NMDA receptors, we used $50 \mu \mathrm{M}$ APV and $20 \mu \mathrm{M}$ MK801 $[(+)$-5-methyl-10,11-dihydro-5H-dibenzo $\quad[\mathrm{a}, \mathrm{d}] \quad$ cyclohepten-5,10imine maleate] (Hoffman et al., 2002). Miniature EPSPs (mEPSPs) were recorded in the presence of $1 \mu \mathrm{M}$ tetrodotoxin, $50 \mu \mathrm{M}$ bicuculline, and 50 $\mu \mathrm{M}$ APV. Intracellular electrodes $(10-15 \mathrm{M} \Omega$ ) contained the following (in mM): $110 \mathrm{~K}$-gluconate, $10 \mathrm{KCl}, 2 \mathrm{MgCl}_{2}, 2 \mathrm{Na}_{2} \mathrm{ATP}, 0.03 \mathrm{Na}_{2} \mathrm{GTP}$, 10 HEPES, and 0.05 picrotoxin, $1 \mathrm{~N}$-nitro-L-arginine (L-NNA), 0.1 $\mathrm{N}$ - $\omega$-nitro-L-arginine methyl ester (L-NAME), and 5 QX314 [2(triethylamino)- $\mathrm{N}$-(2,6-dimethylphenyl) acetamine] for voltageclamp studies, corrected to $\mathrm{pH} 7.3$ (290 mOsm). All drugs were from Tocris Bioscience (Avonmouth, UK) unless otherwise stated. We also used autocamtide-2-inhibitory peptide (AIP) $(0.1-5 \mu \mathrm{M})$ in the electrode solution on occasion. The AIP used was KKALRRQEAVDAL (Calbiochem, Nottingham, UK) described by Ishida et al. (1998).

Spermine NONOate was used to increase nitric oxide (NO) levels in the slice. Levels of NO created by $100 \mu \mathrm{m}$ spermine NONOate were measured using the Griess Reagent System (Promega, Southampton, UK). Briefly, a $50 \mu \mathrm{l}$ sample was incubated in the presence of sulfanilamide, followed by $N$-1-napthylethylenediamine, which causes the conversion of $\mathrm{NO}$ to $\mathrm{NO}_{2}{ }^{-}$. A colorimetric change was measured at a wavelength of $525 \mathrm{~nm}$, and levels were quantified using an $\mathrm{NO}_{2}{ }^{-}$standard curve.

Recording methods. The stimulating electrode was placed accurately within the wall of a layer IV barrel under visual guidance using an Olympus Optical (Tokyo, Japan) BH2 video microscope and a transilluminated slice. Cells were chosen in layer II/III on the nearside of the adjacent barrel column and patched under visual guidance using a $40 \times$ water immersion objective, differential interference contrast optics, and infrared illumination. Stimulation intensity was set to produce an EPSP just above threshold; this minimum stimulation level was used for standard low-frequency stimulation $(0.14 \mathrm{~Hz})$, multipulse stimulation was used for paired-pulse analysis, and presynaptic and postsynaptic action potentials were paired to induce long-term potentiation (LTP).

Whole-cell recordings were made at post-break-in resting membrane potential (average $E_{\mathrm{m}}$ of $-69 \pm 5 \mathrm{mV}$ for wild types, $-71 \pm 4 \mathrm{mV}$ for GluR1 knock-outs) under current clamp but discarded if the series resistance changed by $>20 \%$. Monosynaptic components of the EPSPs had reversal potentials close to $0 \mathrm{mV}$ (average $E_{\mathrm{r}}$ of $3.2 \pm 9.3$ for wild types and $4.3 \pm 8.6$ for GluR1 mutants). LTP was induced by pairing a brief 10 $\mathrm{ms}$ somatic current pulse, sufficient to produce a postsynaptic spike, with the presynaptic stimulus (pre-post interval of $10 \mathrm{~ms}$ ). Two trains of 100 pairs were delivered at a rate of $2 \mathrm{~Hz}$, with a $30 \mathrm{~s}$ gap between the two trains. The change in paired-pulse ratio (PPR), or $\Delta_{\mathrm{PPR}}$ (second response/first response) was defined as the paired-pulse ratio before LTP minus that after LTP.

Silent synapses were tested in the voltage-clamp recording configuration with the addition of $5 \mathrm{~mm}$ QX314 to the recording electrode solution. Cells were recorded from at -70 and $+100 \mathrm{mV}$ to ensure complete reversal of the EPSCs. In cases of magnesium-free experiments, normal aCSF was reversibly substituted for one containing no $\mathrm{Mg}^{2+}$.

In studies in which we evoked delayed and monoquantal events, we added $2 \mathrm{~mm}$ strontium to the extracellular solution (i.e., the solution contained $2 \mathrm{mM} \mathrm{Sr}^{2+}$ and $2 \mathrm{mM} \mathrm{Ca}^{2+}$ ). Strontium EPSPs disparate from the main EPSP but within $400 \mathrm{~ms}$ of its onset were identified by eye and fitted with a double-exponential function (Hardingham and Larkman, 1998), and the amplitudes were recorded.

Miniature EPSPs were recorded and measured from layer II/III pyramidal neurons in the presence of $1 \mu \mathrm{M}$ tetrodotoxin, $50 \mu \mathrm{M} \mathrm{APV}$, and 50 $\mu \mathrm{M}$ bicuculline. After control periods of recording, a solution containing $1 \mu \mathrm{M}$ tetrodotoxin, $50 \mu \mathrm{M} \mathrm{APV}, 50 \mu \mathrm{m}$ bicuculline, and $100 \mu \mathrm{M}$ spermine NONOate was perfused on the slice, and, after 20 min more, miniature EPSPs were recorded. mEPSPs were detected by eye, the rising phase was fitted with an exponential function, and the amplitude was measured (Hardingham and Larkman, 1998).

In drug trials in which we tested the effect of intracellular NO synthase (NOS) inhibitors, we alternated recordings with normal electrode filling solution with recordings with NOS antagonists. Half of the data were collected in this manner and the other half using one electrode solution or the other for several successive recordings. There were no differences between the results obtained using the two methods (average LTP at 60 min for L-NNA treatment: interleaved trials, $11.5 \pm 1.9 \%, n=12$; noninterleaved trials, $13.1 \pm 2.1 \%, n=12 ; t_{(22)}=0.16 ; p=0.87$ ).

Analysis and statistical methods. The basic quantal analysis we performed involved obtaining reliable peak separations in the amplitude histograms to estimate quantal size $(Q)$. Histograms were selected from stable periods of data recording, at least 50 and normally 100 trials long (as indicated in the text). Peak separation was determined by the distribution of the data points when binned finely $(20 \mu \mathrm{V})$. A unimodal distribution was fitted to the data and subtracted from the data to produce a difference function (the deviation of the data from the unimodal distribution). The autocorrelation of the difference function was calculated and tested for its statistical significance using Monte Carlo simulations (Stratford et al., 1997). Only histograms with $p<0.05$ were included in the data. Quantal stability was gauged for EPSP recordings that were stable over $30 \mathrm{~min}$ (in cases in which LTP was not induced). If amplitude histograms showed peaks, we divided the data into two separate epochs and then tested the autocorrelation of the difference function of each epoch for significance using Monte Carlo simulations (Stratford et al., 1997). Data were included in which stable peaks from both periods passed the test. The value for synaptic release $\left(N P_{\mathrm{r}}\right)$ was calculated by dividing the mean amplitude $\left(N P_{\mathrm{r}} Q\right)$ by $Q$.

The locus of potentiation was estimated by comparing the change in EPSP variance with the change in mean amplitude (Malinow and Tsien, 1990), based on the assumption that the transmission being studied conforms to simple binomial statistics (Koester and Johnston, 2005):

$$
\left(\mathrm{CV}^{-2}=\frac{N P_{\mathrm{r}}}{\left(1-P_{\mathrm{r}}\right)}\right)
$$

The mean amplitude and variance were measured for the whole control period plus stable periods of at least 50 (and usually 100) stimuli after pairing using custom software [SYN (Larkman et al., 1997a)]. Three periods were studied, the control period, the first $10 \mathrm{~min}$ of potentiation, and the last $10 \mathrm{~min}$ of potentiation. We calculated the squared coefficient of variation $\mathrm{CV}^{2}$ from the variance and mean amplitude $\left(\mathrm{CV}^{-2}=\right.$ mean $^{2} /$ variance $)$, normalized the mean amplitude and $\mathrm{CV}^{-2}$ values to the control period, and plotted them for the three time periods (see Figs. 3, 7a).

Statistical analysis of LTP data were performed by averaging the data into seven $10 \mathrm{~min}$ time epochs (In which the first $10 \mathrm{~min}$ epoch represented baseline data) and using ANOVA to test for effects of time, genotype, and drug application, together with any interaction terms using the JMP statistical program (JMP, Cary, NC). Post hoc $t$ tests were used to investigate the origin of effects further using an $\alpha$ value of 0.05 . Values of $p$ are as reported in the text.

\section{Results}

Potentiation can be induced in synapses in a variety of ways, and it is not yet clear which of these methods produces an effect most similar to plasticity in vivo. However, there is evidence from whisker deprivation studies in barrel cortex that changes in spike timing drive in vivo plasticity rather than changes in input frequency (Celikel et al., 2004). Because spike timing-dependent 
a

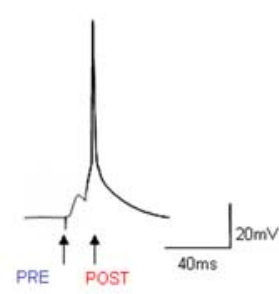

c

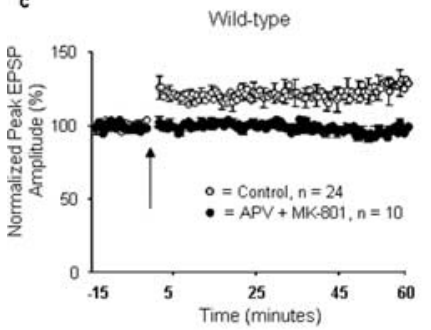

e

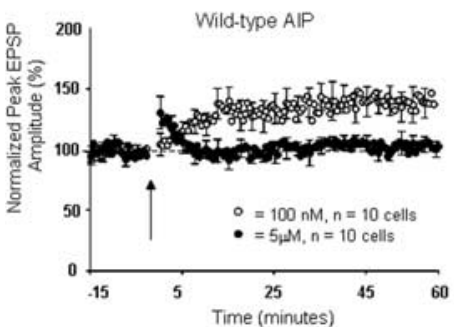

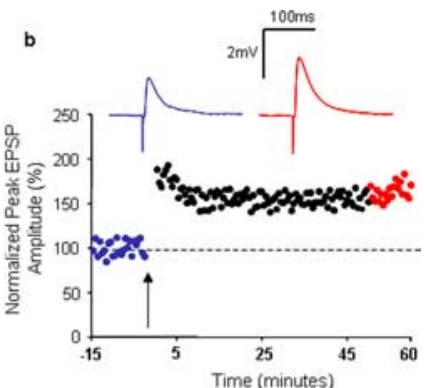
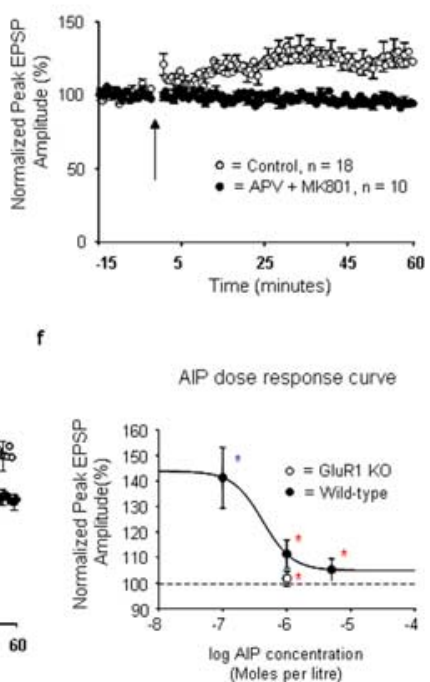

Figure 1. Plasticity in the cortical layer IV to II/III pathway depends on NMDAR and postsynaptic CaMKII. $\boldsymbol{a}$, Inset, STDP is induced by pairing presynaptic and postsynaptic spikes so that the postsynaptic spike occurs $10 \mathrm{~ms}$ after the presynaptic stimulus. In the rest of the figures, pairing is indicated at the time marked by a vertical arrow. $\boldsymbol{b}$, An example of EPSP potentiation after pairing (wild type). The inset EPSPs show average EPSPs before pairing (blue) and 50-60 min after pairing (red). c, In wild types, pairing produces EPSP potentiation (white circles), which is highly significant ( $34 \%$ at 60 min; $t_{(45)}=4.1 ; p<0.0002$ ). However, no potentiation could be induced in the presence of $50 \mu \mathrm{M}$ APV and $20 \mu \mathrm{m}$ MK801 (black circles), and a slight depression of $4 \%$ occurred $\left(t_{(22)}=2.2 ; p<0.05\right)$. $d$, In GluR1 knock-outs (K0), spike pairing produces a slowly rising form of LTP (white circles), which is highly significant ( $24 \%$ at $60 \mathrm{~min} ; t_{(34)}=3.4$ $p<0.002$ ). Potentiation was also blocked in GluR1 knock-outs in the presence of APV and MK801 (black circles; $\left.t_{(20)}=0.1 ; p=0.95\right)$. e, Low doses of AIP (white circles) do not affect LTP $\left(100 \mathrm{~nm} ; F_{(1,1)}=12.5 ; p<0.007\right)$, whereas $5 \mu \mathrm{m}$ AIP (black circles) completely abolishes LTP $\left(F_{(1,1)}=0.05 ; p=0.83\right)$. $f$, Response-inhibition curve for AIP in wild types shown by the solid line [significant potentiation is indicated by a blue star $(p<0.05)$ and no potentiation by a red $\operatorname{star}(p>0.05)]$. A single dose of AIP was tested for GluR1 knock-outs (white circle) at $1 \mu \mathrm{m}$ and again showed inhibition of LTP induction.

plasticity (STDP) acts in a similar manner to other induction methods in barrel cortex (Hardingham et al., 2003) and it may be a more physiologically relevant induction protocol (Celikel et al., 2004), we used it in this study.

\section{The role of NMDA receptors and postsynaptic CaMKII in STDP}

To test whether STDP in the layer IV to II/III pathway of the neocortex is NMDA receptor dependent, as it is in the hippocampus (Hoffman et al., 2002), we evoked EPSPs in layer II/III cells by stimulating layer IV in the neighboring barrel. Potentiation was induced by pairing a presynaptic stimulus to occur $10 \mathrm{~ms}$ before a postsynaptic action potential evoked by somatic current injection (Fig. 1a,b). We found that potentiation was induced in this pathway but was blocked by antagonizing NMDA receptors (Fig. 1c).
We found previously that CaMKII was required for STDP at this synapse (Hardingham et al., 2003), but, to test whether CaMKII acts presynaptically or postsynaptically, we included a CaMKII inhibitor, AIP (Ishida et al., 1998), in the electrode and recorded intracellularly from layer II/III pyramidal cells in barrel cortex. Potentiation was induced in cells treated with low doses (100 nM) of AIP but blocked in cells with higher doses at an $\mathrm{IC}_{50}$ of $500 \mathrm{~nm}$ (Fig. 1e,f). In enzyme assays, $1 \mu \mathrm{M}$ AIP blocks CaMKII activity completely without affecting PKA, PKC, or CaMKIV (Ishida et al., 1998). Therefore, these results imply that postsynaptic CaMKII is required for neocortical LTP.

\section{The role of the GluR1 subunit in cortical STDP}

Because postsynaptic CaMKII is required for LTP, we looked at postsynaptic CaMKII substrates that could be involved. Of some 34 known candidates (Yoshimura et al., 2002) the GluR1 subunit of the AMPA channel is able to affect plasticity most directly, by either insertion of new GluR1 subunits into the synaptic membrane (Hayashi et al., 2000) or changing the AMPA conduction state (Barria et al., 1997); both processes are CaMKII dependent. We therefore studied LTP in the IV to II/III cortical pathway of mice lacking the GluR1 subunit of the AMPA channel. We found that the time course of potentiation was different in the two genotypes. During the first $10 \mathrm{~min}$, potentiation was almost maximal in wild types at $30 \pm 5 \%$ but less than half-maximal in GluR1 knock-outs $10 \pm 6 \%$ (Fig. $1 d$ ), and this difference was significant $\left(t_{(40)}=2.95 ; p<0.006\right)$. Sixty minutes after inducing potentiation with the spike pairing protocol, GluR1 knock-outs appeared to show similar levels of LTP to wild types (mean response as a percentage of baseline, $24 \pm 6 \%$ for GluR1 knock-outs vs $34 \pm$ $5 \%$ for wild types), and the difference was not significant $\left(t_{(40)}=\right.$ $0.88 ; p=0.39)$. In common with wild-type STDP, potentiation in the GluR1 knock-outs depended on both NMDA receptors (Fig. 1d) and postsynaptic CaMKII (Fig. 1f).

The locus of plasticity in wild types and GluR1 knock-outs appeared to be different from that observed in wild types. First, in wild types, the paired-pulse ratio was reduced after LTP (initial mean PPR, 1.08; after LTP mean PPR, $0.91 ; t_{(5)}=4.92 ; p<0.004$, paired $t$ test), but all responses to $20 \mathrm{~Hz}$ stimulation in a five pulse train were potentiated (Fig. 2a,c), suggesting a considerable postsynaptic component to potentiation. In contrast, in GluR1 knock-outs, only the first EPSP in the train increased after LTP induction and other responses were reduced, suggesting an absence of postsynaptic potentiation (Fig. $2 b, d$ ). In GluR1 knockouts, the paired-pulse ratio was also reduced after LTP (initial mean PPR, 1.38; after LTP mean PPR, 0.798; $t_{(5)}=8.47 ; p<$ 0.0001 , paired $t$ test) but considerably more than in wild types. In GluR1 knock-outs, the change in paired-pulse ratio after LTP was greater (PPR change, $0.59 \pm 0.07, n=5$; light gray bar) than in wild types (PPR change, $0.17 \pm 0.03, n=6$; dark gray bar) and was significantly different $\left(t_{(9)}=2.45 ; p<0.002\right)$. Second, the initial paired-pulse ratio was higher in GluR1 knock-outs capable of expressing LTP, suggesting that low release probability synapses (with high PPRs) were more likely to potentiate than high release probability synapses (Fig. 2e). This relationship did not hold for wild types, as would be expected if postsynaptic potentiation mechanisms were also present in these animals.

The presynaptic locus of LTP in GluR1 knock-outs was further corroborated by $\mathrm{CV}^{-2}$ analysis (Malinow and Tsien, 1990). Purely postsynaptic changes would produce a horizontal trajectory in the plot (Fig. 3), whereas changes in $N$ or $P_{\mathrm{r}}$ would cause a more vertical trajectory. This is because $\mathrm{CV}^{-2}$ is proportional to $N P_{\mathrm{r}}\left(1-P_{\mathrm{r}}\right)^{-1}$ and is therefore not dependent on $Q$, whereas the 

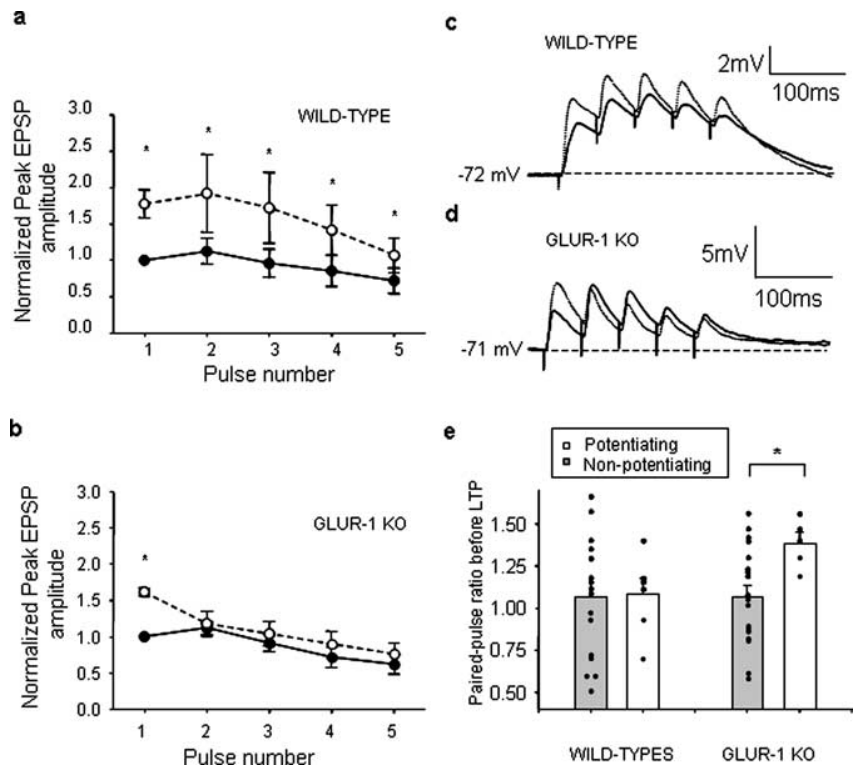

Figure 2. The locus of plasticity expression. $\boldsymbol{a}, \boldsymbol{b}$, Spike pairing potentiates multipulse responses in wild types $\left(F_{(1,1)}=12.5 ; p<0.001\right)$ and GluR1 knock-outs $\left(F_{(1,1)}=7.43 ; p<0.01\right)$. $\boldsymbol{b}$, Pulse number is differentially affected in GluR1 knock-outs $(\mathrm{K} 0)\left(F_{(4,4)}=7.18 ; p<0.002\right)$ because only the first pulse is different from control values $\left(t_{(4)}=11.27 ; p<0.0002\right)$. Example multipulse responses in a wild type (c) and a GluR1 knock-out (d) before (solid line) and after (dashed line) inducing LTP.e, The PPR was only predictive of an ability to undergo LTP in GluR1 knock-outs. The initial PPR before pairing is shown for individual cases by the black circles and the average PPR by the white bars (for potentiators) and gray bars (nonpotentiators).

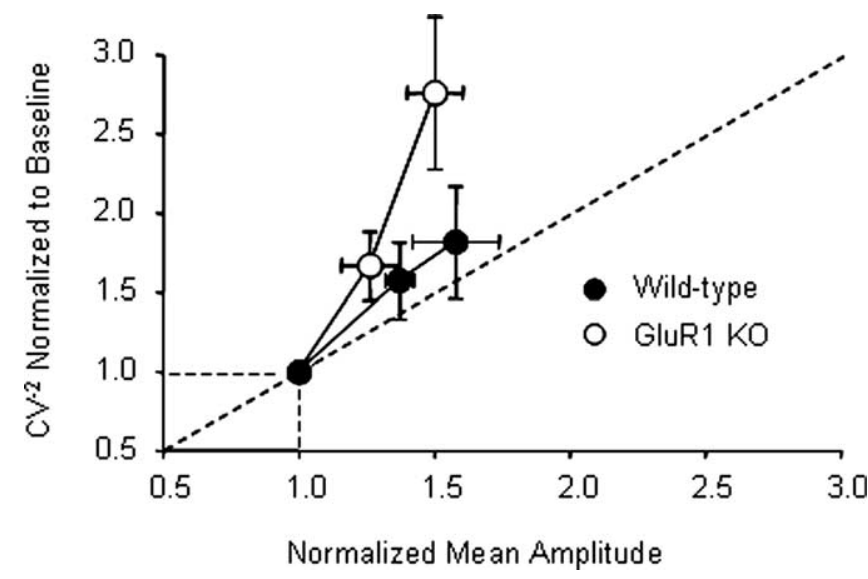

Figure 3. The locus of plasticity in wild types and GluR1 knock-outs. The mean response versus $\mathrm{CV}^{-2}$ trajectory is more vertical for GluR1 knock-outs (K0) (slope of $3.11 \pm 0.46$; white circles) than wild types (slope of mean/ $/ \mathrm{CV}^{-2}$ of $1.67 \pm 0.46$; black circles) and was significantly different at $0-10\left(t_{(18)}=2.21 ; p<0.05\right)$ and $50-60 \mathrm{~min}\left(t_{(18)}=2.19 ; p<0.05\right)$. Note that the first point to the right of the origin $(1,1)$ along each line represents measurements taken during the first $10 \mathrm{~min}$, and the second linked point measurements taken at $50-60 \mathrm{~min}$ after pairing. The origin $(1,1)$ represents the baseline condition before spike pairing, and both $\mathrm{CV}^{-2}$ and mean are normalized to unity.

mean amplitude is proportional to $N P_{\mathrm{r}} Q$ and is therefore dependent on $Q$ (in which $N$ is the number of release site, $P_{\mathrm{r}}$ is the probability of release, and $Q$ is the quantal size). In wild types, the trajectory showed changes in mean amplitude and $\mathrm{CV}^{-2}$, indicative of a presynaptic component to potentiation (Fig. 3). The first points on the line are measures taken for the first $10 \mathrm{~min}$ and the second points 50-60 min after induction of LTP. In GluR1 knock-outs, the trajectory of the $\mathrm{CV}^{-2}$ plot was far steeper than in wild types (wild-type slope, $1.67 \pm 0.46$; GluR1 slope, $3.11 \pm$
0.46 ; $\mathrm{df}=18 ; p<0.03$ ), indicating that the change is predominantly presynaptic in the GluR1 knock-outs.

The conclusions of the paired-pulse analysis were in agreement with the $\mathrm{CV}^{-2}$ analysis in that it also indicated a predominant presynaptic component to LTP in the GluR1 knock-outs and a mixed presynaptic and postsynaptic locus in the wild types. However, we also had an opportunity to check these conclusions using a third method. The amplitude histograms we recorded often had regularly spaced peaks, which is usually indicative of quantal synaptic transmission (Larkman et al., 1997b). We therefore conducted a quantal analysis on cases with clear peak separation (see Materials and Methods) (supplemental Figs. 1-3, available at www.jneurosci.org as supplemental material). Consistent with the multipulse response and $\mathrm{CV}^{-2}$ analysis, quantal analysis showed that, although LTP produced changes in $Q$ as well as in transmitter release $\left(N P_{\mathrm{r}}\right)$ in wild types (Fig. $\left.4 a, b\right)$, LTP in GluR1 knock-outs only produced changes in $N P_{\mathrm{r}}$ (Fig. 4a,c).

Quantal variance was small enough to resolve peaks in amplitude histograms of EPSPs and to determine quantal parameters for a subset of cases. We were able to establish that peak separation for evoked responses corresponded to monoquantal release by additional experiments using desynchronous transmitter release in the presence of strontium (supplemental Fig. 1, available at www.jneurosci.org as supplemental material). In wild types, quantal size increased an average of $37 \pm 11 \%(n=11)$ and $N P_{r}$ by an average of $116 \pm 42 \%$, both of which were highly significant ( $Q$ change, $t_{(10)}=3.9, p<0.005 ; N P_{\mathrm{r}}$ change, $t_{(10)}=2.6, p<$ 0.003 ; paired $t$ tests). These changes could not have come about as a matter of chance or by drift of the recording because $Q$ and $N P_{\mathrm{r}}$ were unchanged over similar time periods when pairing did not produce LTP (average change in $Q, 4 \pm 6 \%$; average change in $N P_{\mathrm{r}},-3 \pm 5.3 \% ; n=6$ ) (supplemental Figs. 2, 3, available at www.jneurosci.org as supplemental material). In GluR1 knockouts, after induction of LTP, quantal size was actually $6 \pm 7 \%$ lower than control levels $(n=7)$. The $Q$ change in wild types was significantly different from the lack of $Q$ change in GluR1 knockouts $\left(t_{(16)}=2.9 ; p<0.02\right)$ (Fig. $\left.4 a\right)$. In GluR1 knock-outs, the quantal variable that did change was presynaptic release $\left(N P_{\mathrm{r}}\right)$, which increased by $131 \pm 27 \%(n=7)$, and was significant $\left(t_{(6)}=\right.$ 3.49; $p<0.02$, paired $t$ test).

Although it is evident that presynaptic forms of LTP dominate in the GluR1 knock-outs, the question arises whether this is attributable to abolishing the postsynaptic component of LTP to reveal the presynaptic component or whether the presynaptic component is enhanced in GluR1 knock-outs to compensate for the loss of the postsynaptic component. To test this idea, we compared the change in $N P_{\mathrm{r}}$ in wild types with that in GluR1 knock-outs. We found that the change in $N P_{\mathrm{r}}$ was indistinguishable between genotypes (Fig. $4 a$ ), indicating a similar degree of presynaptic plasticity in wild types and GluR1 knock-outs and a lack of evidence of enhanced presynaptic plasticity in GluR1 knock-outs $\left(t_{(16)}=0.26 ; p=0.8\right)$.

Induction of LTP in GluR1 knock-outs caused a reduction in response failures without changes in $N$ or $Q$ (Fig. $4 c$ ). Given that the multipulse response analysis implies that a change in $P_{\mathrm{r}}$ occurs in the GluR1 knock-outs (Fig. $2 b, d$ ), the most likely cause of the change in synaptic release $\left(N P_{\mathrm{r}}\right)$ seen in the quantal analysis derives from a change in $P_{\mathrm{r}}$ rather than $N$. This idea is supported further by evidence from the $\mathrm{CV}^{-2}$ analysis. In a mean amplitude versus $\mathrm{CV}^{-2}$ plot, as shown in Figure 3, slopes greater than unity must involve a change in $P_{\mathrm{r}}$, whereas changes in $N$ would cause a linear increase in both $\mathrm{CV}^{-2}$ and mean amplitude and therefore leave the slope unaffected. In addition, changes in $N$ attributable, 
a

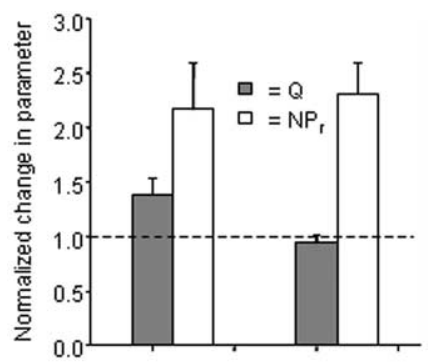

c
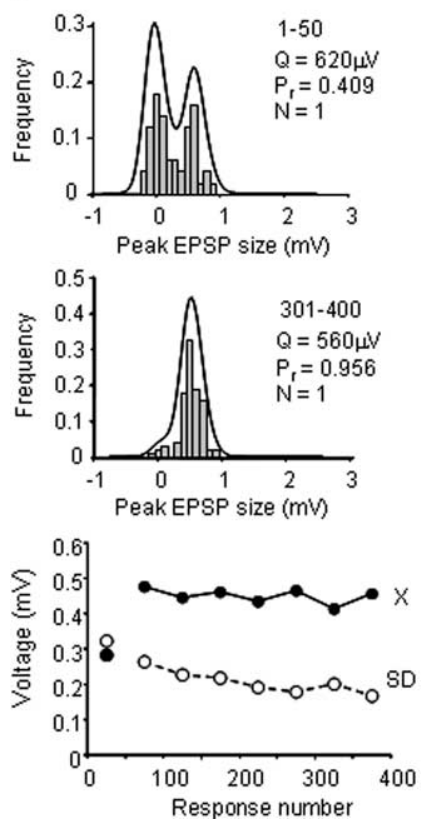

Figure 4. Quantal analysis of the locus of plasticity expression. $\boldsymbol{a}$, In GluR1 knock-outs (K0), $Q$ values after pairing (gray bars) were unchanged at $-6 \pm 7 \%$ (range of -23 to $+23 \%$ ), whereas $N P_{r}$ (white bars) increased by $131 \pm 27 \%$ (range of 90 to $284 \%$ ). In wild types (WT), $Q$ increased by $37 \%$ (range of -10 to $76 \%$ ) and $N P_{r}$ by $116 \%$ (range of 2 to $520 \%$ ) after spike pairing. $\boldsymbol{b}$, Wild-type example: $Q$ increased 10 min after pairing (compare top and middle histograms), and subsequently $P_{r}$ also increased after 50 min (bottom histogram). The bottom graph shows a plot of mean $(x)$ and SD versus stimulus trial number. The trial numbers in the histograms above (see inset) correspond to the trial numbers on the horizontal axis such that the point is plotted in the midpoint of the range (i.e., the 5-100 point is plotted at 75). Note that, in this example, both mean and SD increase after pairing, consistent with an increase in $Q$. c, In GluR1 knock-outs, $P_{r}$ increased after 50-60 min (compare top and bottom histograms), but $Q$ did not (for verification of quantal methods, see supplemental Figs. 1-3, available at www.jneurosci.org as supplemental material). For a simple binomial release, SD is proportional to $Q$ and, in this example, was constant before and after potentiation (bottom graph) (Larkman et al., 1997a).

for example, to unsilencing silent synapses would be unlikely at the ages we studied ( $6-13$ weeks) because silent synapses decrease to very low levels in layer II/III neurons even at 4 weeks of age (Rumpel et al., 2004). In support of this, we found no evidence of silent synapses in this pathway at this age in either GluR1 or wild-type mice (Fig. 5). Two tests for the presence of silent synapses were performed. First, we compared failure rates of responses to presynaptic stimulation in neurons held at either +100 or $-70 \mathrm{mV}$. The positive potentials revealed EPSCs typical of NMDA receptor currents, whereas the negative potentials yielded EPSCs typical of AMPA currents. Silent synapses would have been evident if failures were lower at positive potentials, which was not the case for any cell studied in wild types or GluR1 knock-outs (Fig. 5a,b). Second, we compared failures for cells maintained at a constant $-70 \mathrm{mV}$ in the presence or absence of $\mathrm{Mg}^{2+}$. NMDA receptor currents were revealed in the absence of $\mathrm{Mg}^{2+}$ (Fig. 5f). Failure rates were not higher for EPSCs containing NMDA components than for those lacking NMDA components (mean failure rate, $0.40 \pm 0.05$ in $1 \mathrm{~mm}$ and $0.38 \pm 0.06$ in $\left.0 \mathrm{mM} \mathrm{Mg}{ }^{2+} ; t_{(9)}=0.32 ; p=0.75\right)$. This was the case whether periods of $0 \mathrm{Mg}^{2+}$ preceded periods in $1 \mathrm{mM} \mathrm{Mg}^{2+}$ or vice versa (Fig. 5, compare $f, g$ ). Occasionally, stimulation in the presence of $0 \mathrm{Mg}^{2+}$ caused potentiation of EPSCs that was only revealed on returning to $1 \mathrm{mM} \mathrm{Mg}^{2+}$ (Fig. $5 g$ ). On this occasion, silent synapses were shown not to be present (as is clear from comparing the failure rates in the two preceding periods, one with $\mathrm{Mg}^{2+}$ and one without), and yet failure rate decreased on returning to $1 \mathrm{~mm}$ $\mathrm{Mg}^{2+}$ attributable to an increase in release probability (Fig. $5 g$ ).

All four methods we used to test the locus of LTP in this part of the study led to the same conclusion. Therefore, because wild types show presynaptic and postsynaptic components to LTP expression and yet GluR1 knock-outs show an almost entirely presynaptic locus, these findings imply that the major postsynaptic component of LTP in the neocortex of adult mice depends on the GluR1 subunit.

\section{The role of nitric oxide in cortical STDP}

Because plasticity is induced postsynaptically via CaMKII and yet expressed at least partly presynaptically, we tested to see whether a retrograde messenger might be involved in plasticity at the layer II/III synapse. NOS is both a CaMKII substrate (Bredt et al., 1992; Watanabe et al., 2003) and the source of the retrograde messenger NO implicated in LTP (Son et al., 1996). Postsynaptic NOS activity was attenuated by introducing L-NNA into the intracellular recording electrode. L-NNA reduced potentiation in wild types by $49 \%$ (Fig. 6a). Later components of LTP appeared to be affected most. Whereas mean differences between control and L-NNA-treated cells were $12-14 \%$ over the first $30 \mathrm{~min}$, this increased to $18-20 \%$ over the last $30 \mathrm{~min}$ (Fig. $6 b$ ). Post hoc $t$ tests showed that only responses at time points beyond $30 \mathrm{~min}$ were significantly smaller in L-NNA-treated versus untreated wild types $(p<0.05)$.

Potentiation in the L-NNA-treated wild types appeared to be purely postsynaptic based on three measures. First, potentiation occurred without a change in $\mathrm{CV}^{-2}$ (Fig. $7 a$ ). The trajectory of the normalized mean amplitude versus $\mathrm{CV}^{-2}$ plot was horizontal and therefore suggested no change in $P_{\mathrm{r}}$. Second, potentiated EPSPs lacked any change in paired-pulse response (Fig. 7b). Responses to a multipulse train were characterized by an even increase in the response to all pulses after potentiation and no increase in paired-pulse depression (Fig. 7d,e). Third, whereas $Q$ increased in wild types treated with NOS blockers $\left(t_{(6)}=2.9 ; p<\right.$ 0.03 , paired $t$ test $), N P_{\mathrm{r}}$ did not change significantly $\left(t_{(6)}=1.33\right.$; $p=0.23)$, again suggesting that the presynaptic component of LTP in wild types involves production of NO. Consequently, the change in $Q$ in L-NNA-treated ( $40 \pm 12 \%)$ and untreated (36 \pm $12 \%)$ cells was not significantly different $\left(t_{(15)}=0.20 ; p=0.84\right)$, and transmitter release changed less in L-NNA-treated (11 \pm $10 \%)$ compared with untreated $(76 \pm 14 \%)$ cells $\left(t_{(15)}=3.29\right.$; $p<0.005)$.

In the GluR1 knock-outs, blocking NOS completely blocked potentiation (Fig. 6 c), suggesting that GluR1 and NOS normally act in concert to produce a potentiated state at this synapse. Another non-isoform-specific NOS antagonist, L-NAME, had a similar effect to L-NNA, suggesting that the effect was not specific to a particular compound (Fig. 8). In wild types, L-NAME re- 
duced the average level of potentiation by $61 \%$ at $60 \mathrm{~min}$ after pairing and abolished potentiation in GluR1 knock-outs (Fig. 8).

Induction of LTP in GluR1 knock-outs led to a slowly developing potentiation, rising to its final amplitude after $\sim 20 \mathrm{~min}$ (Fig. 1d), reminiscent of the time course of hippocampal LTP in GluR1 knock-outs (Hoffman et al., 2002). Given that the LTP seen in the GluR1 knock-outs was dependent on nitric oxide and demonstrated a slower time course of expression, we wanted to test whether the delay in expression of the NO component was limited by NO generation or by factors downstream of NO. We therefore performed additional experiments in which we applied an NO donor and measured the time course of changes in EPSP amplitude in layer II/III cells. Figure $9 a$ shows that, after $100 \mu \mathrm{M}$ NO donor application, the EPSP amplitude increases slowly over a period of 20-30 min. NO appeared to act presynaptically because miniature EPSPs (Fig. 9b,c) showed changes in frequency but not amplitude in the presence of the NO donor (rate increase of $32.5 \%, t_{(5)}=4.53, p<$ 0.005 ; amplitude change, $-4 \%, t_{(5)}=$ $0.47, p=0.65)$. The cumulative distribution function for the mEPSP amplitude shows that the amplitudes are the same for control and NO donor cases (Fig. 9d). These results are consistent with LTP induction almost immediately releasing $\mathrm{NO}$, followed by a slower response to NO by rate-limiting steps downstream of the retrograde messenger. It is unlikely that the slow time course is explained by slow diffusion of NO into the tissue, because this small weakly polar molecule is highly diffusible in the brain (Lancaster, 1997; Philippides et al., 2005). The slow expression of NO-dependent presynaptic plasticity would also explain why NOS inhibitors appear to have a greater effect on LTP in wild types at later time points (Fig. $6 a, b$ ).

\section{Discussion}

In this study, we have been able to separate the presynaptic and postsynaptic components of potentiation in adult neocortex using quantal analysis, paired-pulse analysis, $\mathrm{CV}^{-2}$ analysis, NOS inhibitors, and GluR1 knock-outs. Convergent findings from all five methods have allowed us to distinguish a substantial component of LTP that is NO dependent in cortex, which appears to form the presynaptic component of LTP at the synapse we are studying. Similarly, the residual postsynaptic component appears to be GluR1 dependent.

Previous studies on the role of NO in hippocampal plasticity have not lead to a firm conclusion on its role in mature animals. However, there has been consistent evidence for a presynaptic component to plasticity in the neocortex from several groups over many years (Markram and Tsodyks, 1996; Sjostrom et al., b

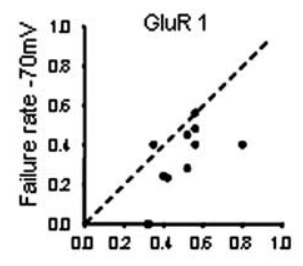

C

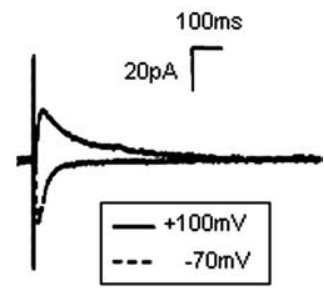

Failure rate $+100 \mathrm{mV}$

e

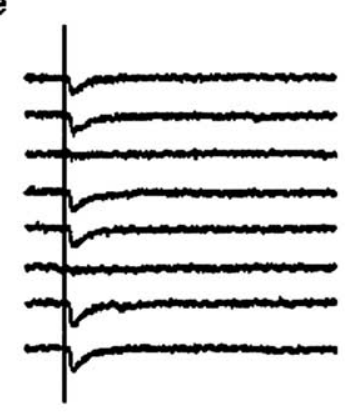

g

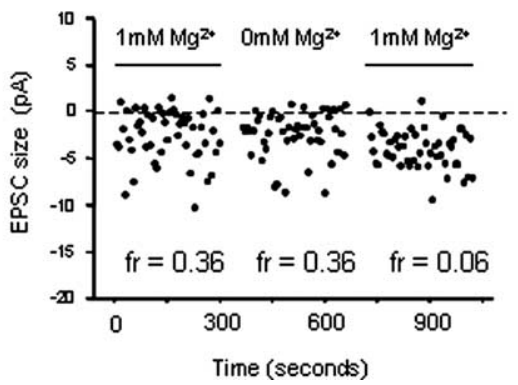

Figure 5. Tests for the presence of silent synapses. $\boldsymbol{a}$, In wild types, failure rates were approximately equal for holding potentials of +100 and $-70 \mathrm{mV}$, and in no case were failure rates higher at negative potentials. $\boldsymbol{b}, \ln$ GluR1 knock-outs, failure rates were again not greater at negative than positive potentials. 0 average, there were no difference between failure rates at positive and negative potentials in both wild types $\left(t_{(14)}=5.7 ; p<0.001\right)$ and GluR1 knock-outs $\left(t_{(9)}=4.5 ; p<0.0001\right)$.c , At positive holding potentials (solid line), EPSCs were outward and of long duration comparable with EPSCs containing NMDA receptor currents. At negative potentials (dashed line), EPSCs were inward, briefer, and comparable with AMPA currents. $\boldsymbol{d}$, An example of the evoked EPSCs recorded at positive potentials for eight successive stimuli. $\boldsymbol{e}$, The evoked EPSCs recorded from the same cell show no more failures at negative potentials. $f$, Failure rates did not decrease when EPSCs were recorded in $0 \mathrm{Mg}^{2+}$ compared with the response of the same cell in $1 \mathrm{~mm} \mathrm{Mg}^{2+}$. In this example, the experiment starts in $0 \mathrm{Mg}^{2+}$. The insets show currents corresponding to periods of 50 stimuli in each solution. Note that the currents increase in duration in $0 \mathrm{Mg}^{2+}$ (pairedpulse stimulation was used; $100 \mathrm{~ms}$ between stimuli). Calibration: 5 pA, $100 \mathrm{~ms}$. $\boldsymbol{g}$, Failure rates were not decreased when magnesium was removed from the solution in cases in which the recording began in $1 \mathrm{~mm}$ magnesium. Note that failure rates were stable during both periods of $1 \mathrm{~mm} \mathrm{Mg}^{2+}$. Occasionally, as with this case, neurons showed potentiation on exposure to $0 \mathrm{Mg}^{2+}$ that was only apparent on returning to $1 \mathrm{~mm} \mathrm{Mg}^{2+}$, presumably because of an increase in $P_{\mathrm{r}}$ fr, Failure rate.

2003) and specific evidence that nitric oxide might be involved (Haul et al., 1999; Volgushev et al., 2000). A number of factors may have hampered experimenters from obtaining unambiguous results in the past. The first concerns the fact that, in wild types, synapses are a heterogeneous population, some showing more presynaptic LTP than others. This has been commented on by Volgushev et al. (2000) in visual cortex who found that synapses showing high levels of initial paired-pulse ratio were more likely to potentiate than those showing low levels of PPR. We reproduced this result for the GluR1 knock-outs in the barrel cortex (Fig. 2e), but, in wild types, the initial level of PPR was not predictive of ability to potentiate, presumably because postsyn- 
$\mathbf{a}$
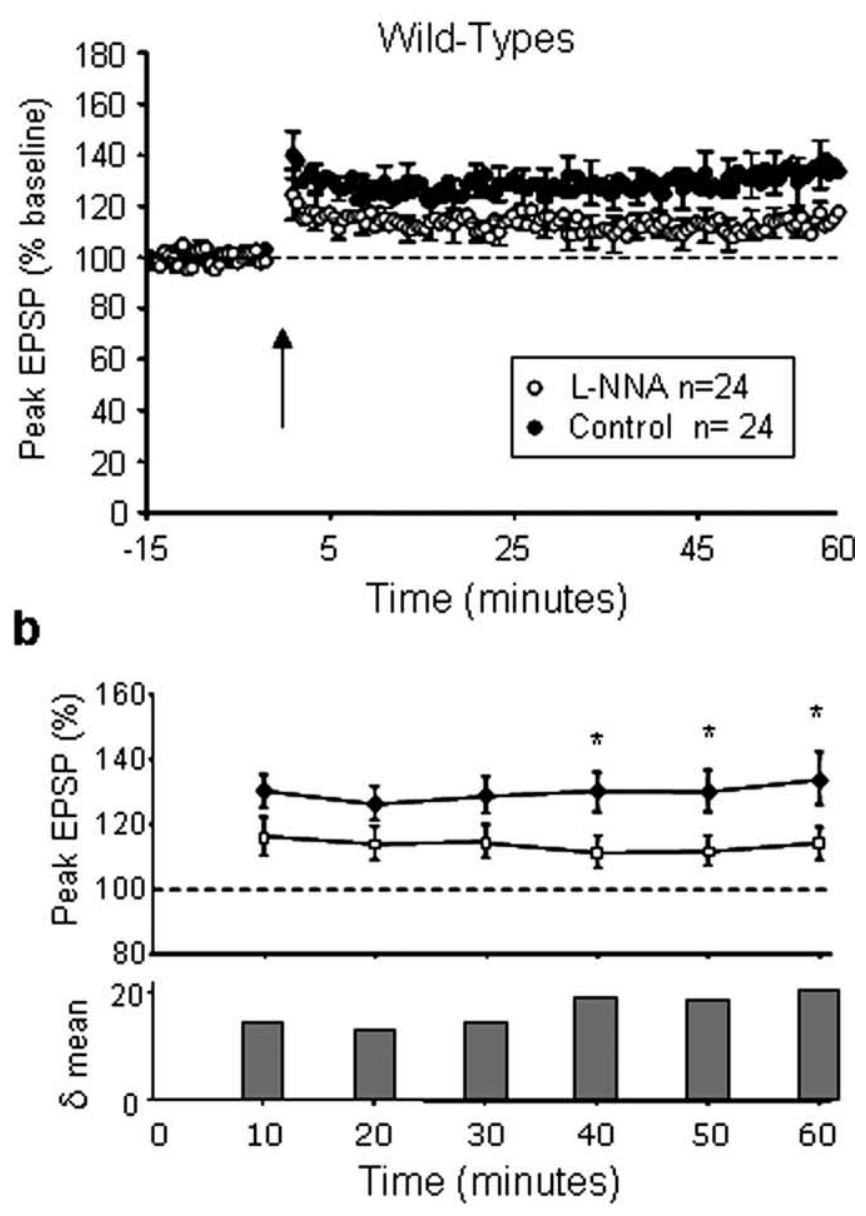

C

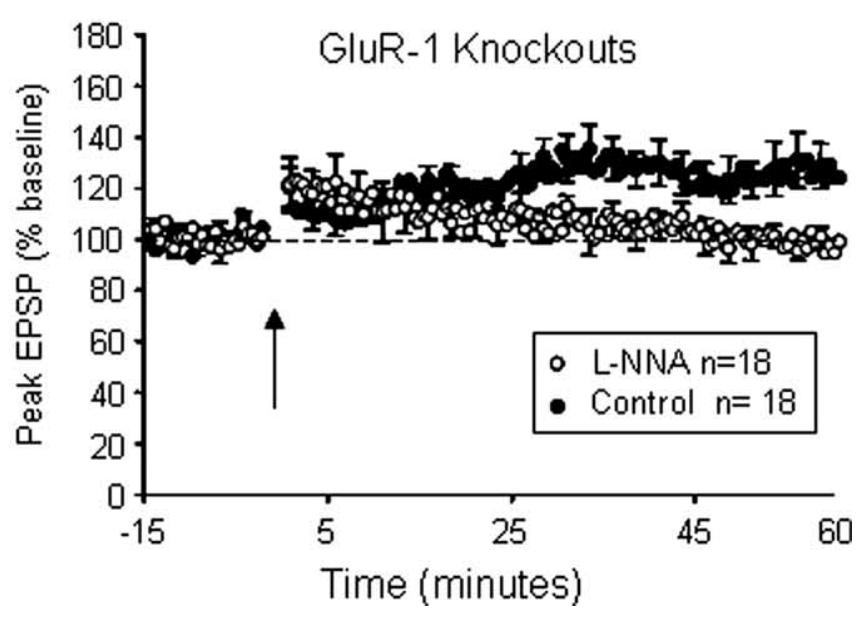

Figure 6. Effect of NOS inhibition on potentiation in wild types and GluR1 knock-outs. $\boldsymbol{a}$, Wild types: -NNA significantly reduced potentiation $\left(F_{(1,1)}=24.25 ; p<10^{-3}\right)$ but only beyond $30 \mathrm{~min}$ ( $\alpha=0.05, t$ tests). Black circles represent peak EPSP measures taken from wild-type layer II/III cells recorded with normal electrode filling solution (see Materials and Methods), whereas L-NNA was included in the electrode solution for the cases shown by the white circles. $\boldsymbol{b}$, The same wild-type data as in $\boldsymbol{a}$ is replotted in $10 \mathrm{~min}$ epochs. The difference between the control and L-NNA-treated means is shown in the histogram. The difference in the mean amplitudes increases with time and are only significantly different for time points at 40 , 50 , and 60 min as indicated by the asterisks ( $\alpha=0.05, t$ test). c, GluR1 knock-outs: L-NNA abolishes $\operatorname{LTP}\left(F_{(1,1)}=15.16 ; p<10^{-4}\right)$ at all time points beyond $10 \mathrm{~min}(\alpha=0.05, t$ tests). Black circles are for control, and white circles are for L-NNA containing electrode solution.

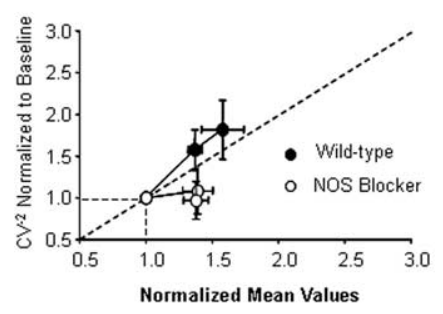

C
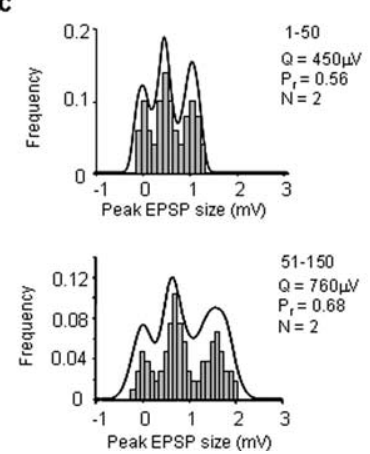

Figure 7. Inhibition of NOS isolates postsynaptic potentiation in wild types. $\boldsymbol{a}$, Mean response versus $\mathrm{CV}^{-2}$ trajectory is significantly different and almost flat (slope of $0.28 \pm 0.41$ ) in L-NNA-treated (white circles) compared with control (black) wild types $\left(t_{(13)}=2.81 ; p<0.02\right)$, indicating a primarily postsynaptic locus for LTP. The first point on the trajectory is measured at $0-10 \mathrm{~min}$ and the second at $50-60 \mathrm{~min}$ after pairing. The origin $(1,1)$ represents the baseline condition before spike pairing, and both $\mathrm{CV}^{-2}$ and mean are normalized to unity. $\boldsymbol{b}$, Pairedpulse ratio changes in wild types (WT) and GluR1 knock-outs (K0) after LTP but not in wild types treated with L-NNA ( $\Delta_{\mathrm{PPR}}=0.05 \pm 0.08 ; n=5$ ) (leftmost bar). c, Amplitude histograms mainly showed changes in $Q$ when wild-type cells were treated with NOS inhibitors. In this example, control values of $Q$ (top histogram) increase by $68 \%$ after LTP (bottom histogram) from 450 to $760 \mu \mathrm{V}$, whereas $P_{\mathrm{r}}$ changed by a far smaller amount (from 0.56 to 0.68 ). $\boldsymbol{d}$, An example of a multipulse response in a wild-type cell treated with intracellular L-NNA before (solid line) and after (dashed line) potentiation. $\boldsymbol{e}$, The same example as in $\boldsymbol{d}$ except the potentiated trace has been scaled down so that the first EPSP is the same amplitude as the pre-LTP response and slightly offset in time. Note that the traces are almost identical, indicating that potentiation is not attributable to a change in transmitter release.

aptic mechanisms were still available for potentiation in neurons with a low paired-pulse ratio. The ability to undergo presynaptic LTP varies from one cell to another because of the heterogeneity of synaptic connections, and therefore the effect of NOS antagonists also varies for different cells. Indeed, it would have been difficult to dissociate the role of NO in neocortical plasticity unambiguously in the wild types were it not for the fact that the GluR1 knock-outs show primarily presynaptic LTP.

The heterogeneity of wild-type LTP makes it difficult to see a difference in the absolute level of potentiation in wild types and GluR1 knock-outs at the 60 min time point. Many of the wildtype cells showed predominantly presynaptic LTP, similar to the GluR1 knock-outs, and would therefore be expected to show similar levels of potentiation. One would only expect to see greater potentiation in the wild types in cases in which both presynaptic and postsynaptic components were present, and, although this often occurred, their effect on the average level of potentiation was diluted by the cases in which it did not. The argument in favor of a role for GluR1 in LTP at this synapse therefore comes not so much from the lower level of potentiation in GluR1 knock-outs compared with wild types but from the fact that GluR1 knock-outs show little or no postsynaptic component to LTP, whereas the wild types clearly do.

However, the wild types and GluR1 knock-outs did show a 


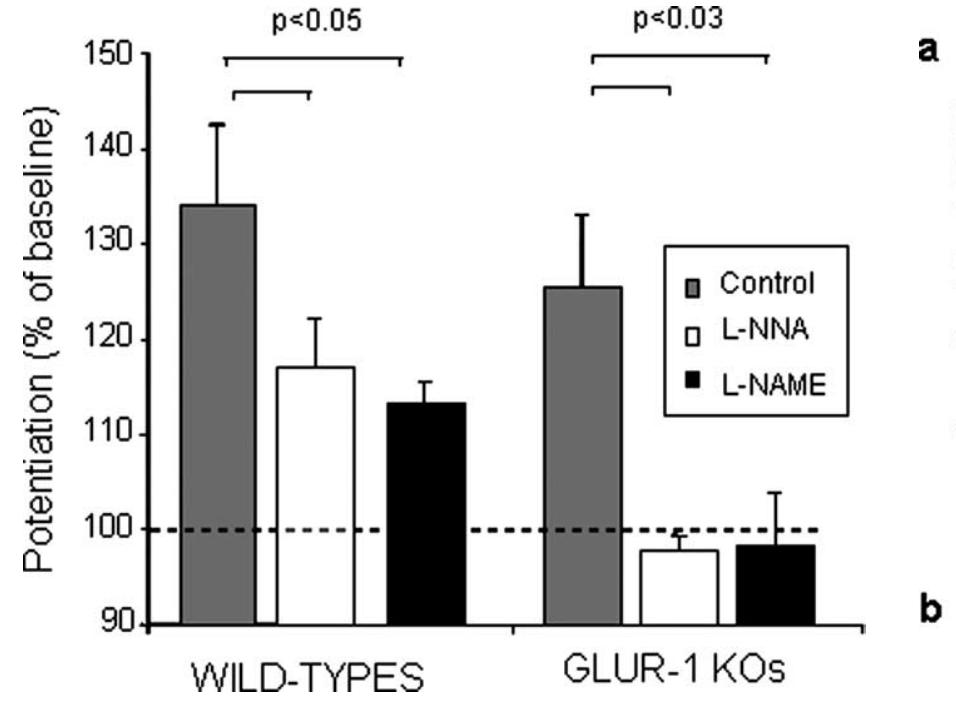

Figure 8. Summary of the effect of nitric oxide synthase antagonists on wild types and GluR1 knock-outs. Potentiation at 50-60 min after pairing for all treatment groups shows that NOS inhibitors reduce potentiation in wild types to $\sim 50 \%$ of control levels (left, L-NNA, white bars, $n=24 ;$ L-NAME, black bars, $n=18$ ) and abolishes potentiation in GluR1 knock-outs (KO) (right, L-NNA, white bars, $n=18$; L-NAME, white bars, $n=10$ ). Significance levels are shown for comparison between conditions.

clear difference in the magnitude of LTP 10 min after pairing presynaptic and postsynaptic action potentials, principally because the GluR1 knock-outs show very little LTP of any sort at this time point. A similar time course has been described by Hoffman et al. (2002) for LTP in CA1 hippocampal cells. A plausible explanation for this effect is that factors downstream of nitric oxide release take at least $10 \mathrm{~min}$ to produce an increase in transmitter release after pairing, an idea that is supported by our finding that a nitric oxide donor produces a slowly rising form of potentiation (Fig. 9).

In this study, we concentrated on LTP in adult (6-13 weeks) rather than developing animals principally because it may relate to the adult plasticity induced in vivo in layer II/III cells by whisker deprivation (Hardingham et al., 2003). However, the majority of the literature on in vitro plasticity in neocortex relates to juvenile animals, and it may therefore be worthwhile to point out some of the differences between our observations and those made in juveniles. First, studying adults made it extremely unlikely that we were observing a reduction in failures during LTP attributable to unsilencing silent synapses. Silent synapses are at high levels during development (Isaac et al., 1997) but are practically absent in layer II/III cortical cells beyond 4 weeks of age (Rumpel et al., 2004). The youngest animals in our studies were 6 weeks of age, with the majority being older than 8 weeks. As confirmation of this point, we also found no evidence of silent synapses in these neurons in our own studies (Fig. 5). Second, it allowed us to use quantal analysis techniques. To be successful, quantal analysis requires low levels of quantal variance, and this is aided by the fact that quantal variance decreases with age (Wall and Usowicz, 1998). We also confirmed that the peaks we identified in our amplitude histograms did indeed correspond to monoquantal responses (supplemental Figs. 1-3, available at www.jneurosci.org as supplemental material). Third, we routinely found connections yielding paired-pulse ratios of greater than unity. This is different from the findings in layer II/III cells at $17-23 \mathrm{~d}$ of age, for example (Reyes and Sakmann, 1999; Feldmeyer et al., 2002), but entirely consistent with findings in animals over $28 \mathrm{~d}$ of age

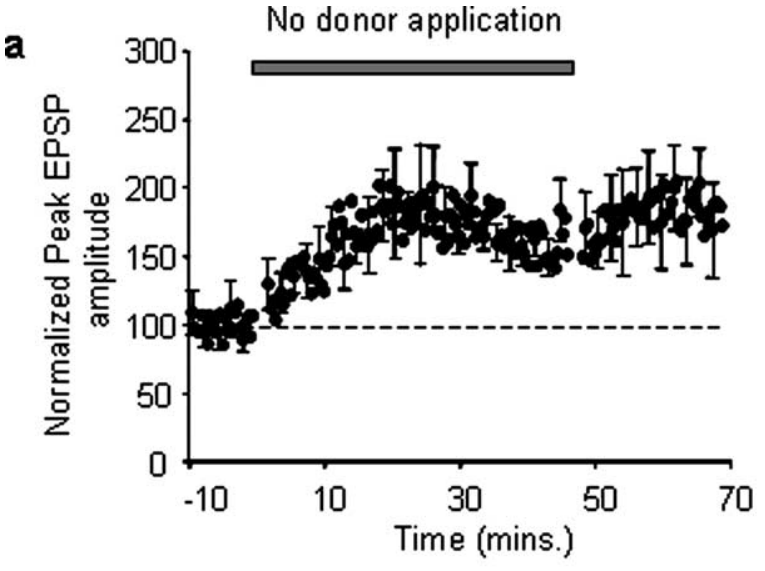

b

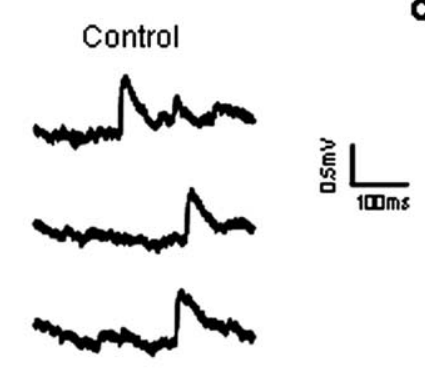

NO Donor

d

Cumulative distribution function for EPSP amplitude

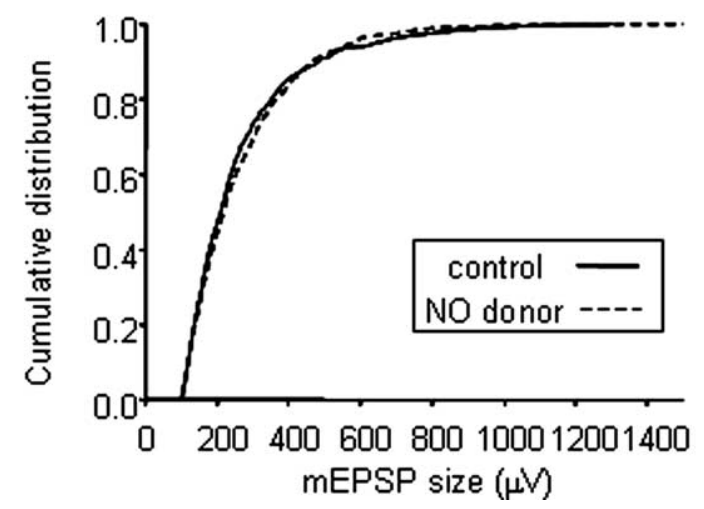

Figure 9. Time course and locus of NO donor effects. $\boldsymbol{a}$, Spermine NONOate $(100 \mu \mathrm{M})$ significantly increases peak EPSPs in layer II/III cells $\left(F_{(6)}=5.49 ; p<0.0004\right)$. The concentration of $\mathrm{N} 0$ in the extracellular solution was measured as $40 \mu \mathrm{m}$ using the Griess method (see Materials and Methods). Example mEPSPs from wild types before drug application (b) and with NO donor present $(c)$. The NO donor increased the frequency but not the size of mEPSPs, indicating a presynaptic site of action (see Results).

(Reyes and Sakmann, 1999). Clearly, synaptic physiology changes with age and our results here relate to adult but not juvenile animals.

The finding that NO is involved in plasticity at cortical layer II/III cells leads to the question of where NOS might be located. At a cellular level, in mature neocortex, NOS is densely localized in inhibitory cells and diffusely distributed elsewhere (Imura et al., 2005). The diffuse component appears to be relevant to neocortical LTP because it is spatially related to the source of NO release after NMDA receptor activation (Imura et al., 2005). Conversely, NMDA-dependent NO release has not been observed from the densely stained inhibitory cells. It appears that endothe- 
lial NOS (eNOS) is localized to the membrane by myristolation (Busconi and Michel, 1993), whereas neural NOS (nNOS) can be linked to the NMDA receptor by postsynaptic density-95 (Brenman et al., 1996). Previous studies have implicated both eNOS (Kantor et al., 1996; Haul et al., 1999) and nNOS (Son et al., 1996) in LTP. Recent evidence from cultured hippocampal cells has also shown that NO may have both presynaptic and postsynaptic effects (Wang et al., 2005). The present study shows that, over the time course of $60 \mathrm{~min}$, the effect of NO is presynaptic at the IV to II/III synapse in the neocortex.

The present evidence shows that the GluR1 subunit of the AMPA channel is important for postsynaptic neocortical plasticity. GluR1 may exert an effect by increasing AMPA channel conductivity after phosphorylation at the Ser ${ }^{831}$ CaMKII site or because GluR1 is necessary for activity-dependent insertion into the postsynaptic membrane (Barria et al., 1997; Hayashi et al., 2000). The latter process is also CaMKII dependent and relies on interactions between the C-terminal tail of the GluR1 subunit and other proteins. We assume that the GluR4 subunit, which also has a similar long C-terminal tail, does not compensate for GluR1 in the adult mice we studied here because it is mainly present early in development (Rossner et al., 1993). Theoretically, the long-tail form of GluR2 could have compensated for the lack of GluR1 (Kolleker et al., 2003), but our results suggest it does not do so.

The computational consequences of a presynaptic form of LTP are quite different from those of a postsynaptic mechanism. Whereas postsynaptic LTP leads to a simple gain change in the synaptic response, presynaptic LTP alters the frequency response of the synapse as release probability is increased (Markram and Tsodyks, 1996). The effect of potentiating a cortical synapse with both presynaptic and postsynaptic mechanisms would be to both increase its gain and move its bandwidth to lower frequencies. Our studies suggest that synapses with both mechanisms are common in mature cortex.

A number of models have been formulated that capture the properties of dynamic synapses, and, although it is possible to see how such networks can retain memories (Carpenter and Milenova, 2002; Abbott and Regehr, 2004), to our knowledge, no clear computational advantage of a system involving presynaptic components to plasticity has yet been described. However, it is of interest that GluR1 knock-outs have been reported to exhibit working memory deficits but not reference memory deficits (Schmitt et al., 2005). This is consistent with the time course of the faster and more transient GluR1 component of potentiation described here and in previous studies in the hippocampus (Hoffman et al., 2002), because working memory operates on the scale of minutes. By inference, the reference memory that remains intact would most probably rely on presynaptic mechanisms were that memory to be cortically located. The present finding that the presynaptic and postsynaptic forms of neocortical plasticity can be dissociated by independent manipulation of GluR1 and NO should enable additional investigation of the computational and cognitive consequences of presynaptic and postsynaptic potentiation mechanisms in the neocortex.

\section{References}

Abbott LF, Regehr WG (2004) Synaptic computation. Nature 431:796-803. Allen PB, Hvalby O, Jensen V, Errington ML, Ramsay M, Chaudhry FA, Bliss TV, Storm-Mathisen J, Morris RG, Andersen P, Greengard P (2000) Protein phosphatase-1 regulation in the induction of long-term potentiation: heterogeneous molecular mechanisms. J Neurosci 20:3537-3543.

Barria A, Muller D, Derkach V, Griffith LC, Soderling TR (1997) Regulatory phosphorylation of AMPA-type glutamate receptors by CaM-KII during long-term potentiation. Science 276:2042-2045.
Bredt DS, Ferris CD, Snyder SH (1992) Nitric oxide synthase regulatory sites. Phosphorylation by cyclic AMP-dependent protein kinase, protein kinase $\mathrm{C}$, and calcium/calmodulin protein kinase; identification of flavin and calmodulin binding sites. J Biol Chem 267:10976-10981.

Brenman JE, Chao DS, Gee SH, McGee AW, Craven SE, Santillano DR, Wu Z, Huang F, Xia H, Peters MF, Froehner SC, Bredt DS (1996) Interaction of nitric oxide synthase with the postsynaptic density protein PSD-95 and alpha1-syntrophin mediated by PDZ domains. Cell 84:757-767.

Buonomano DV (1999) Distinct functional types of associative long-term potentiation in neocortical and hippocampal pyramidal neurons. J Neurosci 19:6748-6754.

Buonomano DV, Merzenich MM (1998) Cortical plasticity: from synapses to maps. Annu Rev Neurosci 21:149-186.

Busconi L, Michel T (1993) Endothelial nitric oxide synthase. N-terminal myristoylation determines subcellular localization. J Biol Chem 268:8410-8413.

Carpenter GA, Milenova BL (2002) Redistribution of synaptic efficacy supports stable pattern learning in neural networks. Neural Comput 14:873-888.

Celikel T, Szostak VA, Feldman DE (2004) Modulation of spike timing by sensory deprivation during induction of cortical map plasticity. Nat Neurosci 7:534-541.

Feldman DE (2000) Timing-based LTP and LTD at vertical inputs to layer II/III pyramidal cells in rat barrel cortex. Neuron 27:45-56.

Feldmeyer D, Lubke J, Silver RA, Sakmann B (2002) Synaptic connections between layer 4 spiny neurone-layer $2 / 3$ pyramidal cell pairs in juvenile rat barrel cortex: physiology and anatomy of interlaminar signalling within a cortical column. J Physiol (Lond) 538:803-822.

Finnerty GT, Roberts LS, Connors BW (1999) Sensory experience modifies the short-term dynamics of neocortical synapses. Nature 400:367-371.

Fox K (1994) The cortical component of experience-dependent synaptic plasticity in the rat barrel cortex. J Neurosci 14:7665-7679.

Fox K (2002) Anatomical pathways and molecular mechanisms for plasticity in the barrel cortex. Neuroscience 111:799-814.

Glazewski S, Chen CM, Silva A, Fox K (1996) Requirement for alphaCaMKII in experience-dependent plasticity of the barrel cortex. Science 272:421-423.

Hardingham NR, Larkman AU (1998) Rapid report: the reliability of excitatory synaptic transmission in slices of rat visual cortex in vitro is temperature dependent. J Physiol (Lond) 507:249-256.

Hardingham N, Glazewski S, Pakhotin P, Mizuno K, Chapman PF, Giese KP, Fox K (2003) Neocortical long-term potentiation and experiencedependent synaptic plasticity require $\alpha$-calcium/calmodulin-dependent protein kinase II autophosphorylation. J Neurosci 23:4428-4436.

Haul S, Godecke A, Schrader J, Haas HL, Luhmann HJ (1999) Impairment of neocortical long-term potentiation in mice deficient of endothelial nitric oxide synthase. J Neurophysiol 81:494-497.

Hayashi Y, Shi SH, Esteban JA, Piccini A, Poncer JC, Malinow R (2000) Driving AMPA receptors into synapses by LTP and CaMKII: requirement for GluR1 and PDZ domain interaction. Science 287:2262-2267.

Hoffman DA, Sprengel R, Sakmann B (2002) Molecular dissection of hippocampal theta-burst pairing potentiation. Proc Natl Acad Sci USA 99:7740-7745.

Imura T, Kanatani S, Fukuda S, Miyamoto Y, Hisatsune T (2005) Layerspecific production of nitric oxide during cortical circuit formation in postnatal mouse brain. Cereb Cortex 15:332-340.

Isaac JT, Crair MC, Nicoll RA, Malenka RC (1997) Silent synapses during development of thalamocortical inputs. Neuron 18:269-280.

Ishida A, Shigeri Y, Tatsu Y, Uegaki K, Kameshita I, Okuno S, Kitani T, Yumoto N, Fujisawa H (1998) Critical amino acid residues of AIP, a highly specific inhibitory peptide of calmodulin-dependent protein kinase II. FEBS Lett 427:115-118.

Kantor DB, Lanzrein M, Stary SJ, Sandoval GM, Smith WB, Sullivan BM, Davidson N, Schuman EM (1996) A role for endothelial NO synthase in LTP revealed by adenovirus-mediated inhibition and rescue. Science 274:1744-1748.

Koester HJ, Johnston D (2005) Target cell-dependent normalization of transmitter release at neocortical synapses. Science 308:863-866.

Kolleker A, Zhu JJ, Schupp BJ, Qin Y, Mack V, Borchardt T, Kohr G, Malinow R, Seeburg PH, Osten P (2003) Glutamatergic plasticity by synaptic delivery of GluR-B(long)-containing AMPA receptors. Neuron 40:1199-1212. 
Lancaster Jr JR (1997) A tutorial on the diffusibility and reactivity of free nitric oxide. Nitric Oxide 1:18-30.

Larkman AU, Jack JJ, Stratford KJ (1997a) Assessment of the reliability or amplitude histograms from excitatory synapses in rat hippocampal CA1 in vitro. J Physiol (Lond) 505:443-456.

Larkman AU, Jack JJ, Stratford KJ (1997b) Quantal analysis of excitatory synapses in rat hippocampal CA1 in vitro during low-frequency depression. J Physiol (Lond) 505:457-471.

Malenka RC, Bear MF (2004) LTP and LTD: an embarrassment of riches. Neuron 44:5-21.

Malinow R, Tsien RW (1990) Presynaptic enhancement shown by wholecell recordings of long-term potentiation in hippocampal slices. Nature 346:177-180.

Markram H, Tsodyks M (1996) Redistribution of synaptic efficacy between neocortical pyramidal neurons. Nature 382:807-810.

Nicoll RA, Malenka RC (1995) Contrasting properties of two forms of longterm potentiation in the hippocampus. Nature 377:115-118.

Philippides A, Ott SR, Husbands P, Lovick TA, O’Shea M (2005) Modeling cooperative volume signaling in a plexus of nitric-oxide-synthaseexpressing neurons. J Neurosci 25:6520-6532.

Reyes A, Sakmann B (1999) Developmental switch in the short-term modification of unitary EPSPs evoked in layer 2/3 and layer 5 pyramidal neurons of rat neocortex. J Neurosci 19:3827-3835.

Rossner S, Kumar A, Kues W, Witzemann V, Schliebs R (1993) Differential laminar expression of AMPA receptor genes in the developing rat visual cortex using in situ hybridization histochemistry. Effect of visual deprivation. Int J Dev Neurosci 11:411-424.

Rumpel S, Kattenstroth G, Gottmann K (2004) Silent synapses in the immature visual cortex: layer-specific developmental regulation. J Neurophysiol 91:1097-1101.

Schmitt WB, Sprengel R, Mack V, Draft RW, Seeburg PH, Deacon RM, Rawlins JN, Bannerman DM (2005) Restoration of spatial working memory by genetic rescue of GluR-A-deficient mice. Nat Neurosci 8:270-272.

Sjostrom PJ, Turrigiano GG, Nelson SB (2003) Neocortical LTD via coincident activation of presynaptic NMDA and cannabinoid receptors. Neuron 39:641-654.
Son H, Hawkins RD, Martin K, Kiebler M, Huang PL, Fishman MC, Kandel ER (1996) Long-term potentiation is reduced in mice that are doubly mutant in endothelial and neuronal nitric oxide synthase. Cell $87: 1015-1023$.

Stratford KJ, Jack JJ, Larkman AU (1997) Calibration of an autocorrelationbased method for determining amplitude histogram reliability and quantal size. J Physiol (Lond) 505:425-442.

Takahashi T, Svoboda K, Malinow R (2003) Experience strengthening transmission by driving AMPA receptors into synapses. Science 299:1585-1588.

Volgushev M, Balaban P, Chistiakova M, Eysel UT (2000) Retrograde signalling with nitric oxide at neocortical synapses. Eur J Neurosci 12:4255-4267.

Wall MJ, Usowicz MM (1998) Development of the quantal properties of evoked and spontaneous synaptic currents at a brain synapse. Nat Neurosci 1:675-682.

Wang HG, Lu FM, Jin I, Udo H, Kandel ER, de Vente J, Walter U, Lohmann SM, Hawkins RD, Antonova I (2005) Presynaptic and postsynaptic roles of NO, cGK, and RhoA in long-lasting potentiation and aggregation of synaptic proteins. Neuron 45:389-403.

Watanabe Y, Song T, Sugimoto K, Horii M, Araki N, Tokumitsu H, Tezuka T, Yamamoto T, Tokuda M (2003) Post-synaptic density-95 promotes calcium/calmodulin-dependent protein kinase II-mediated Ser847 phosphorylation of neuronal nitric oxide synthase. Biochem J 372:465-471.

Woolsey TA, Van der Loos H (1970) The structural organization of layer IV in the somatosensory region (SI) of mouse cerebral cortex. The description of a cortical field composed of discrete cytoarchitectonic units. Brain Res 17:205-242.

Yasuda H, Barth AL, Stellwagen D, Malenka RC (2003) A developmental switch in the signaling cascades for LTP induction. Nat Neurosci 6:15-16.

Yoshimura Y, Shinkawa T, Taoka M, Kobayashi K, Isobe T, Yamauchi T (2002) Identification of protein substrates of $\mathrm{Ca}^{2+} /$ calmodulindependent protein kinase II in the postsynaptic density by protein sequencing and mass spectrometry. Biochem Biophys Res Commun 290: 948-954. 